\title{
Expression of Foxp3 and Rorc Genes in Patients Undergoing Allogeneic Hematopoietic Cell Transplantation: Impact in the Development of Acute and Chronic Graft-Versus-Host Disease
}

\author{
Camila Marca de Veiga Cabral, ${ }^{1,2}$, Walter Moises Tobias Braga ${ }^{1}$, Adriano de Moraes \\ Arantes $^{1}$, José Salvador Rodrigues de Oliveira ${ }^{1,2}$, Gisele Wally Braga Colleoni ${ }^{* *}$ and Fábio \\ Rodrigues Kerbauy ${ }^{1 \#}$
}

${ }^{1}$ Departamento de Oncologia Clínica e Experimental, Disciplina de Hematologia e Hemoterapia, Universidade Federal de São Paulo [UNIFESP], São Paulo, Brazil

${ }^{2}$ Serviço de Hematologia e Transplante de Medula Óssea, Casa de Saúde Santa Marcelina [CSSM], São Paulo, Brazil

${ }^{\#}$ Equal contribution.

*Corresponding author: Camila MV Cabral, MD, PhD, and Gisele WB Colleoni, MD, PhD, Departamento de Oncologia Clínica e Experimental, Disciplina de Hematologia e Hemoterapia, Universidade Federal de São Paulo [UNIFESP], São Paulo, Brazil, Tel: (55-11)-5576-4848 ext 2628, Fax: (55-11)-5571-8806

\begin{abstract}
The aim of this study is to characterize Treg (FOXP3) and Th17 (RORC)-related genes in patients who underwent hematopoietic cell transplantation (HCT) and correlate them with graft-versus-host disease (GVHD) onset and patients' outcome. Fifty-one patients undergoing allogeneic HCT from matched related donors (MRD) were studied. Samples were collected before HCT, at acute (aGVHD) or chronic GVHD (cGVHD) onset, and 90 days post-HCT for those who did not have signs of aGVHD. FOXP3 and RORC gene expressions were assessed by real-time PCR (qPCR) as representatives of Treg and Th17 cells, respectively. We found increased expression of proinflammatory Th-17 related $R O R C$ in cGVHD compared with patient without GVHD; also, we found decrease in Treg-related FOXP3 expression in the samples at the time of GVHD when compared to its respective samples before HCT. Although these results could have therapeutic relevance, we could not identify genes' expression values to be used to predict GVHD onset, overall survival, non-relapse or relapse-related mortality.
\end{abstract}

\section{Keywords}

Regulatory T cells, FOXP3, Th17 cells, RORC, Graft-versus-host disease, Hematopoietic cell transplantation

\begin{abstract}
Abbreviations
ACTB: Beta ( $\beta$ )-actin; aGVHD: Acute Graft-versus-host Disease; BGUS: Beta ( $\beta$ ) Glucuronidases; cGVHD: Chronic Graft-versus-host Disease; CT: Threshold Cycle; D+90: 90 Days after Transplant; FOXP3: Forkhead Box Protein 3; GADPH: Glyceraldehyde 3-phosphate Dehydrogenase; GVHD: Graft-versus-host Disease; GVT: Graft Versus Tumor; HCT: Hematopoietic Cell Transplantation; HLA: Human Leukocyte Antigen; IL: Interleukin; MRD: Matched Related Donor; NIH: National Institutes of Health; NRM: Non-relapse Mortality; OS: Overall Survival; qPCR: Quantitative Real-time PCR; RORC: RAR Related Orphan Receptor; Th17: T-Helper-17 Cell; Treg: T Regulatory Cell
\end{abstract}

\section{Introduction}

Graft versus host disease (GVHD) is a leading cause of morbidity and mortality following hematopoietic cell transplantation (HCT) [1]. Despite prophylactic immunosuppression, GVHD occurs in up to $50 \%$ of the patients, and innovative strategies to prevent and treat it are urgently needed. GVHD involves dysregulation of inflammatory cytokine cascades and donor cellular response against host antigens $[2,3]$. $\mathrm{CD} 4^{+} \mathrm{T}$ cells play a critical role in mediating GVHD and understanding the

Citation: Cabral CMV, Braga WMT, Arantes AM, de Oliveira JSR, Colleoni GWB, et al. (2018) Expression of Foxp3 and Rorc Genes in Patients Undergoing Allogeneic Hematopoietic Cell Transplantation: Impact in the Development of Acute and Chronic Graft-Versus-Host Disease. Int J Blood Res Disord 5:032. doi.org/10.23937/2469-5696/1410032

Accepted: September 05, 2018: Published: September 07, 2018

Copyright: (C) 2018 Cabral CMV, et al. This is an open-access article distributed under the terms of the Creative Commons Attribution License, which permits unrestricted use, distribution, and reproduction in any medium, provided the original author and source are credited. 
role of each subset of these lymphocytes in the development of GVHD is critical to discover effective therapy and improve HCT outcome $[4,5]$.

The challenge in allogeneic HCT is to find a balance between beneficial and harmful T-cell effects [6]. CD4 ${ }^{+}$ $\mathrm{CD}^{2} 5^{+} \mathrm{FOXP3}^{+}$Regulatory $\mathrm{T}$ (Treg) cells are key immunoregulatory cell population involved in the maintenance of immune tolerance and have been used to prevent and treat GVHD [4,7]. Murine GVHD models have demonstrated that depletion of $\mathrm{CD} 25^{+}$Tregs promotes GVHD $[8,9]$ while, conversely, infusion of in vitro expanded $\mathrm{CD}^{+} \mathrm{CD}^{+} 5^{+}$Tregs can either prevent or treat GVHD $[10,11]$. Similar to mouse models, Tregs in the peripheral blood of human HCT recipients have been reported to be lower in the presence of acute GVHD (aGVHD) $[4,12,13]$. However, in chronic GVHD (cGVHD), this correlation between increased Tregs and decreased risk of GVHD has been absent $[14,15]$ or even reversed [16].

In contrast, Th17 effector lymphocytes are related to GVHD onset through its main transcription factor RAR related orphan receptor $(R O R C)$, triggering the production of proinflammatory cytokines, such as IL-17A, IL-17F, IL-21 and IL-22 [17-19]. Adoptive transfer of in vitro-differentiated Th17 cells is capable of inducing lethal acute GVHD [20]. However, the role of IL-17 itself on GVHD progression is currently controversial [21-23].

In this context, it is clearly necessary to understand the role of these effector cells and target antigens for pathogenesis of graft-versus-tumor (GVT) effect [24]. Standardization of new techniques, such as the use of molecular biology as a tool to detect the behavior of the immune system in the post-HCT, particularly of T lymphocyte subpopulations, can be helpful to adopt cell therapy and is of fundamental importance to the development of new prophylactic and therapeutic strategies for this clinical syndrome. Therefore, the aim of this study was to characterize the expression of FOXP3 and $R O R C$ genes in peripheral blood of 51 patients who underwent allogeneic HCT from human leukocyte antigen (HLA) identical matched related donors (MRD) and correlate them with the development of acute and chronic GVHD. Furthermore, we aimed to determine the utility of both genes as GVHD biomarkers and their impact in clinical outcome after HCT.

\section{Methods}

\section{Patients and transplantation procedures}

It is a retrospective analysis of blood samples from a biorepository consisting of peripheral blood samples from 89 consecutive patients undergoing allogeneic HCT from MRD, from May 2004 to August 2007, in two Brazilians centers. All samples were collected within 24 hours of clinical signs of aGVHD or cGVHD onset, prior to initiation of corticosteroid therapy, after informed consent signature. In addition, samples were collected before HCT and at day +90 in patients who did not develop aGVHD. Among 89 patients, 51 were eligible for this study. Exclusion criteria were: Sepsis, sinusoidal obstruction syndrome, cytomegalovirus infection or others untreated infections during bone marrow recovery, benign hematologic diseases, relapsed leukemia, death, and failure to collect/technical problems. GVHD was histologically confirmed in $88 \%$ of patients and was staged using modified Gluksberg criteria for aGVHD [25] and NIH 2005 Criteria for cGVHD [26]. All patients underwent allogeneic $\mathrm{HCT}$ from MRD, with unmanipulated grafts. Thirty-five peripheral blood samples of blood donor volunteers were used as the control group.

\section{RNA extraction}

Mononuclear cells from peripheral blood were separated by Ficoll-Hypaque ${ }^{\circledR}$, according to the manufacturer's instructions, from $10 \mathrm{~mL}$ peripheral blood collected in EDTA. Immediately after this, and without previous sorting of specific cell types, total RNA extraction was performed using Trizol reagent (Invitrogen, Carslbad, CA, USA) following the manufacturer's instructions and stored at $-80^{\circ} \mathrm{C}$ until the time of use. The quality of samples was confirmed in $2 \%$ agarose gel stained with Sybr Safe. RNA concentrations were evaluated in spectrophotometer (NanoDrop, Wilmington, Delaware, USA).

\section{Real time quantitative PCR (qPCR)}

In this study qPCR technique was used due to the availability of an RNA Biobank from peripheral blood samples of patients undergoing allogeneic HCT at different times, before and after transplantation. PCR was performed using FOXP3 (Hs01085834_m1) and RORC (Hs01076112_m1) specific primers and probes using the 7500 Fast Real Time PCR System (Applied Biosystems, Foster City, CA). Briefly, experiments were performed using universal PCR Master Mix (Applied Biosystems, Foster City, CA), by Taqman method. To calculate the expression level of each gene in the samples, relative quantification was performed using the $2^{-\Delta \Delta C T}$ method [27]. Results were normalized based on the amplification of three genes: ACTB, BGUS e GAPDH (TaqMan ${ }^{\circledR}$ Endogenous Control). All samples were analyzed in triplicate [28].

\section{Statistical analysis}

To compare FOXP3 and RORC expression in the different groups we used nonparametric Kruskal-Wallis test and, in cases of significant differences between the groups, we performed multiple comparisons by Mann-Whitney test with Bonferroni corrections. To evaluate the differences between the expression of FOXP3 and RORC in the same patient before transplant and at the time of GVHD, we used non-parametric Wilcoxon test for paired data. ROC curves were constructed to evaluate the sensitivity, specificity, and positive and negative predictive values of FOXP3 and RORC expression for acute and chronic GVHD. Overall survival 
(OS) was calculated from the date of transplant until death or last follow-up. Actuarial probabilities of OS were estimated according to the Kaplan-Meier method and the curves were compared using the log-rank test. Differences with a $p<0.05$ were statistically significant. Statistical analysis was performed using SPSS Software version 14.0 (SPSS Inc., Chicago, IL) and Graphpad Prism 5 software (GraphPad, San Diego, CA).

\section{Results}

\section{Patients and transplant characteristics}

Fifty-one adult allogeneic HCT recipients were enrolled in this study. Demographic and transplantation information are summarized in (Table 1). The median age of the patients was 36 years, ranging from 16 to 69 years. $53 \%$ were male and $47 \%$ female. Acute leukemia/

Table 1: Patients characteristics and transplantation details $(N=51)$.

\begin{tabular}{|c|c|c|c|}
\hline Characteristics & $\begin{array}{l}\text { Cases } \\
\mathrm{N}=51(\%)\end{array}$ & $\begin{array}{l}\text { Healthy Controls } \\
\text { (Peripheral blood donors) } \\
\mathrm{N}=35(\%)\end{array}$ & P Value \\
\hline \multicolumn{4}{|l|}{ Gender } \\
\hline Female & $24(47 \%)$ & $16(46 \%)$ & $P>0.05$ \\
\hline Male & $27(53 \%)$ & $19(54 \%)$ & \\
\hline \multicolumn{4}{|l|}{ Age (years) Median (range): 36 (16-69) } \\
\hline$<=20$ & $07(14 \%)$ & $03(09 \%)$ & $P>0.05$ \\
\hline $21-40$ & $22(43 \%)$ & $19(54 \%)$ & \\
\hline$>40$ & $22(43 \%)$ & $13(37 \%)$ & \\
\hline \multicolumn{4}{|l|}{ Diagnosis } \\
\hline AML, ALL, ABL, MDS & $31(61 \%)$ & & \\
\hline $\mathrm{HL}, \mathrm{NHL}$ & $11(21 \%)$ & & \\
\hline Chronic myeloid leukemia & $08(16 \%)$ & & \\
\hline Multiple Myeloma & $01(02 \%)$ & & \\
\hline \multicolumn{4}{|l|}{ Stem cell source } \\
\hline Peripheral blood & $39(77 \%)$ & & \\
\hline Bone marrow & $12(23 \%)$ & & \\
\hline \multicolumn{4}{|l|}{ Intensity Conditioning } \\
\hline Myeloablative & $42(82 \%)$ & & \\
\hline Reduced Intensity Regimen/Nonmyeloablative & $09(18 \%)$ & & \\
\hline \multicolumn{4}{|l|}{ GVHD prophylaxis } \\
\hline Cyclosporine + Methotrexate & $46(90 \%)$ & & \\
\hline Cyclosporine + Mycophenolate mofetil & $05(10 \%)$ & & \\
\hline \multicolumn{4}{|l|}{ Days to GVHD onset (Median) } \\
\hline Acute GVHD (range) & $40(18-70)$ & & \\
\hline Chronic GVHD (range) & $178(117-270)$ & & \\
\hline \multicolumn{4}{|l|}{ Acute GVHD } \\
\hline No & $28(55 \%)$ & & \\
\hline Yes & $23(45 \%)$ & & \\
\hline \multicolumn{4}{|l|}{ Chronic GVHD } \\
\hline No & $20(39 \%)$ & & \\
\hline Yes & $31(61 \%)$ & & \\
\hline \multicolumn{4}{|l|}{ Onset acute GVHD grade } \\
\hline Grade I & $02(09 \%)$ & & \\
\hline Grade II & $11(48 \%)$ & & \\
\hline Grade III-IV & $10(43 \%)$ & & \\
\hline \multicolumn{4}{|l|}{ Onset chronic GVHD grade } \\
\hline Mild & $03(10 \%)$ & & \\
\hline Moderate & $05(16 \%)$ & & \\
\hline Severe & $23(74 \%)$ & & \\
\hline \multicolumn{4}{|l|}{ Organ target at acute GVHD onset } \\
\hline Skin only & $01(04 \%)$ & & \\
\hline Gut only & $0(0.0 \%)$ & & \\
\hline Liver only & $0(0.0 \%)$ & & \\
\hline Skin + gut/liver & $22(96 \%)$ & & \\
\hline
\end{tabular}




\begin{tabular}{l|l}
\hline Organ target at chronic GVHD onset & \\
Skin & $25(81 \%)$ \\
Eyes & $13(42 \%)$ \\
Mouth & $26(84 \%)$ \\
Gastrointestinal tract & $16(52 \%)$ \\
Liver & $15(48 \%)$ \\
Lung & $5(16 \%)$ \\
Joints or fascia & $4(13 \%)$ \\
\hline
\end{tabular}

AML: Acute Myeloid Leukaemia; ALL: Acute Lymphoid Leukaemia; ABL: Acute Biphenotypic Leukaemia; MDS: Myelodysplastic Syndrome; HL: Hodgkin Lymphoma; NHL: Non-Hodgkin's Lymphoma; GVHD: Graft-Versus Host Disease.

A.

$\mathrm{p}=0.0006$

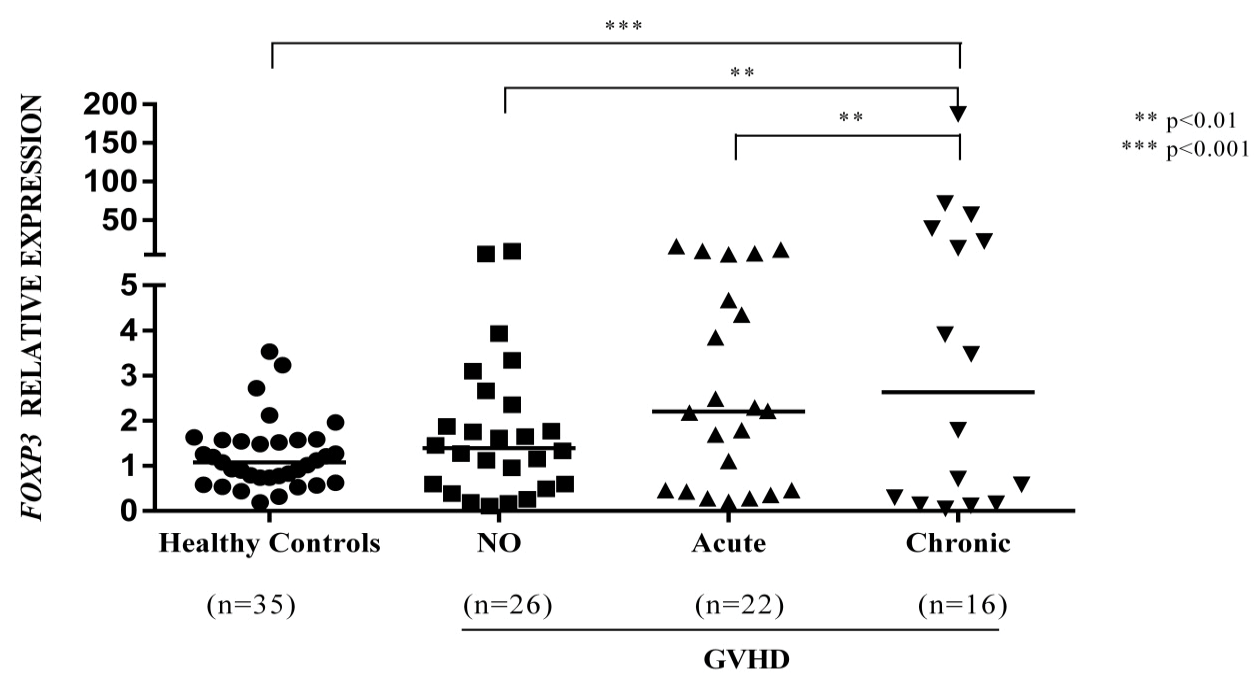

B.

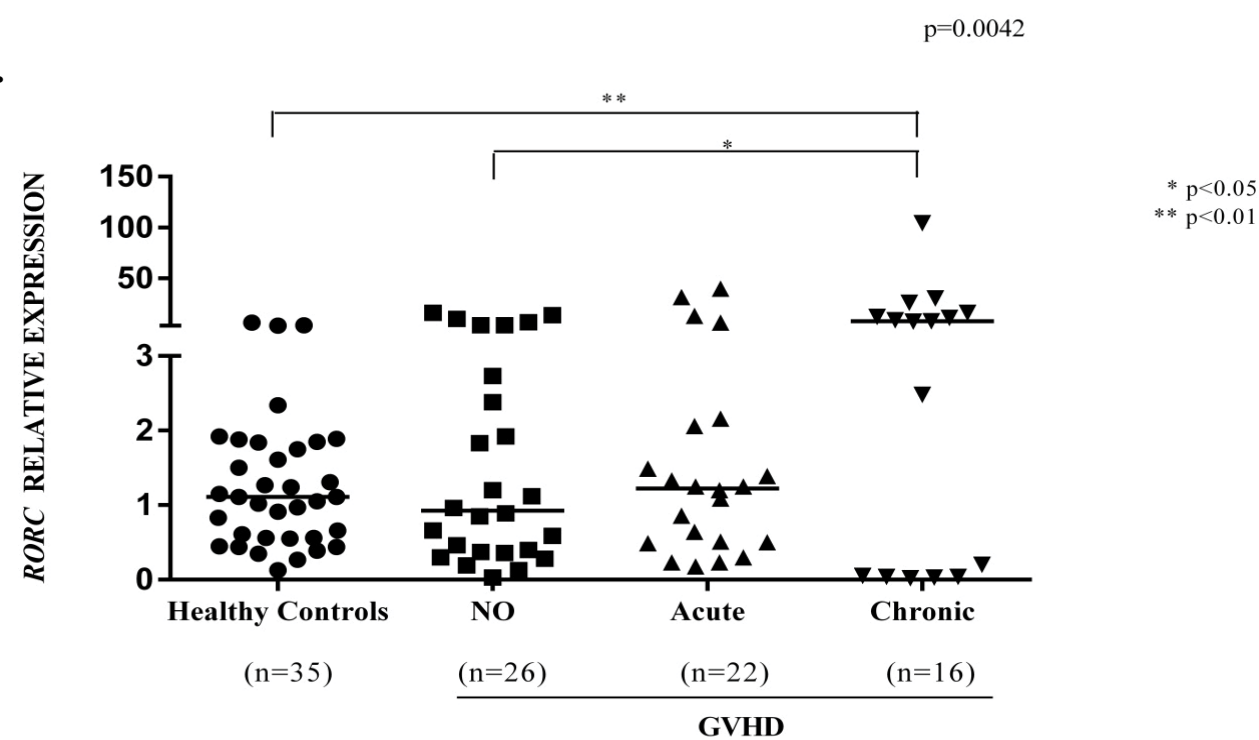

Figure 1: Relative expression $\left(2^{-\Delta \Delta C T}\right)$ of $F O X P 3(\mathrm{~A})$ and $R O R C(\mathrm{~B})$ in peripheral blood of 51 patients and 35 healthy controls before HCT, without GVHD, aGVHD, cGVHD. We found statistically significant differences when controls, no GVHD, aGVHD and cGVHD where analyzed for FOXP3 $(p=0.006)$ and RORC expression $(p=0.0042)$ (Kruskal-Wallis test followed by Mann-Whitney test, with Bonferroni posttest). Other comparisons showed no statistical differences, including comparisons between acute and chronic GVHD for RORC gene expression $p=0.56$ ).

myelodysplastic syndrome was the main transplant indication corresponding to $61 \%$ of patients and the majority of them (39\%) have refractory disease at the time of HCT. The source of hematopoietic cells was CD34+ mobilized from peripheral blood in $77 \%$ of cases, $82 \%$ received myeloablative conditioning regimens being busulfan plus cyclophosphamide the conditioning regimen in $51 \%$ of cases. $90 \%$ of patients received methotrexate combined to cyclosporine as post HCT immunosuppression. During the follow-up period, 10 patients $(20 \%)$ did 
not develop any GVHD, 10 (20\%) showed only aGVHD, $18(35 \%)$ cGVHD and 13 (25\%) patients developed both

A.

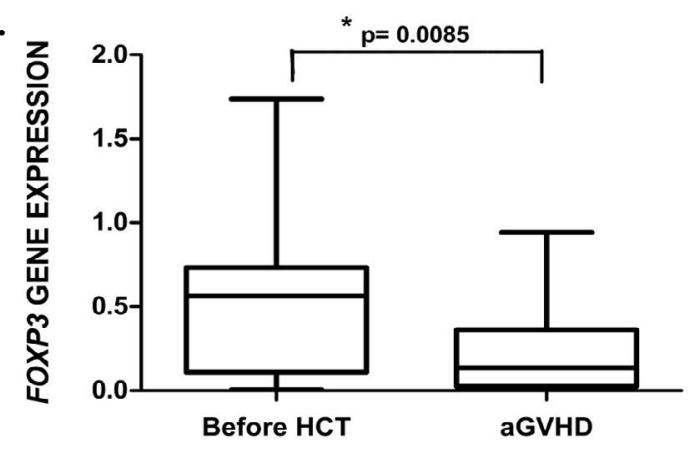

B.

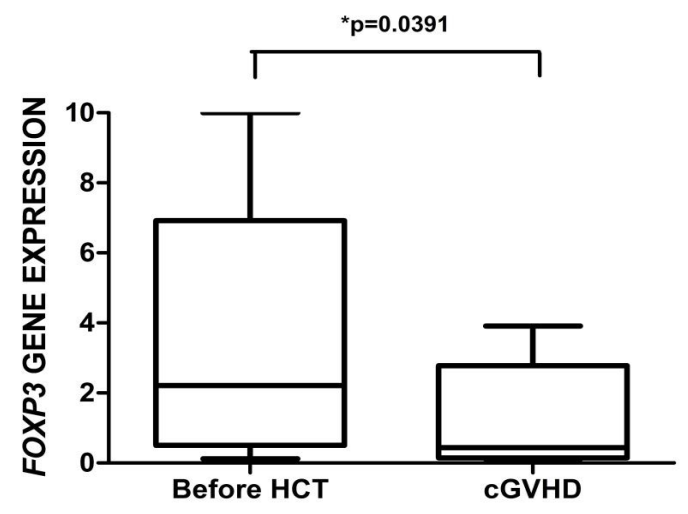

C.

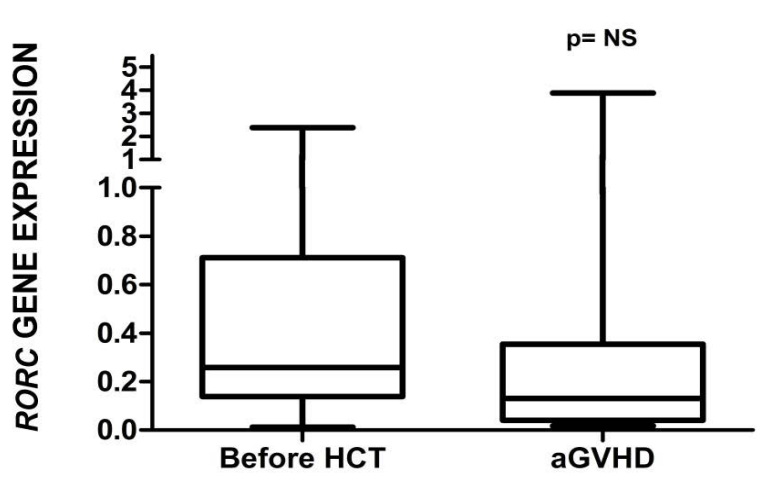

D.

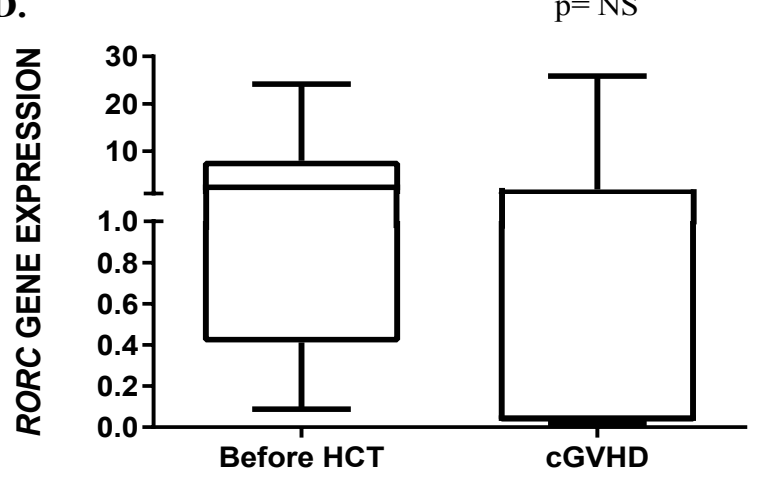

Figure 2: A) Paired analysis of 16 patients comparing samples before HCT and their respective samples at aGVHD onset: The expression of FOXP3 decreased at aGVHD onset $(p=0.0085)$; B) paired analysis of 8 patients comparing samples before HCT and their respective samples at cGVHD onset $(p=0.0391) ; R O R C$ gene expression prior to acute (C) and chronic (D) GVHD onset: We did not find any statistically significant correlation with $R O R C$ expression at aGVHD or cGVHD onset ( $p>0.05$, Wilcoxon test).
aGVHD and cGVHD. Median follow-up was 43.3 months (range, 1.3 to 101.7).

\section{FOXP3 and RORC expression and GVHD correlation}

We found statistically significant differences when healthy controls, no GVHD, aGVHD and cGVHD where analyzed for FOXP3 $(p=0.006)$ and RORC expression $(p=0.0042$ ) (Figure 1, Kruskal-Wallis test followed by Mann-Whitney test, with Bonferroni posttest). Among them, the clinically relevant information is: The increase of FOXP3 in CGVHD group compared with aGVHD and patients without GVHD (Figure $1 \mathrm{~A}$ ) and the increase of $R O R C$ expression in CGVHD compared with patient without GVHD (Figure 1B).

After this global analysis, samples of sixteen patients before HCT and their respective samples at aGVHD onset were evaluated in a paired analysis Figure 2. The expression of FOXP3 decreased at aGVHD onset $(p=$ 0.0085 , Figure $2 \mathrm{C}$ ), whereas no increase was observed in RORC expression at aGVHD onset ( $p>0.05$, Figure 2B). Similarly, when performing paired analysis of eight patients who developed CGVHD, there was a decrease of FOXP3 expression ( $p=0.0391$, Figure 2B) at cGVHD onset but we did not find any statistically significant correlation with RORC expression at CGVHD onset $(p>0.05$, Figure 3D).

\section{FOXP3 and RORC expression as GVHD biomarkers}

ROC curves were constructed to evaluate FOXP3 and $R O R C$ expression for aGVHD and CGVHD, using samples before GVHD as controls. The AUC value obtained for relative expression of FOXP3 in aGVHD was 0.554 , with $p>0.05$. Therefore, we do not find a marker capable of differentiating transplanted patients and pre-GVHD controls. The same occurred for both genes, FOXP3 and $R O R C$, in aGVHD or CGVHD (Table 2). In this scenario, the ideal value of FOXP3 and RORC relative expression to express high sensitivity and specificity was not found (Table 2).

\section{FOXP3 and RORC expression and HCT outcomes}

Overall survival (OS) at 1 year was $60.8 \%$. During the follow up, there were 29 deaths: Eight (28\%) related to disease relapse and $21(78 \%)$ attributable to transplantation-related events. Five (24\%) patients died from aGVHD, nine (43\%) from cGVHD complications and seven (33\%) from infection. OS curves were built using the

Table 2: Roc curve details for FOXP3 and RORC expression in acute and chronic GVHD. AUC-ROC, area under the curve.

\begin{tabular}{|l|l|l|l|l|}
\hline \multirow{2}{*}{ Acute GVHD } & AUC-ROC IC 95\% & p \\
\cline { 2 - 5 } & & Lower & Higher & \\
\hline FOXP3 & 0.554 & 0.4101 & 0.6992 & 0.4753 \\
\hline RORC & 0.529 & 0.3796 & 0.6789 & 0.7027 \\
\hline Chronic GVHD & & & & \\
\hline FOXP3 & 0.514 & 0.3168 & 0.7130 & 0.8619 \\
\hline RORC & 0.621 & 0.3869 & 0.8560 & 0.1675 \\
\hline
\end{tabular}


A.
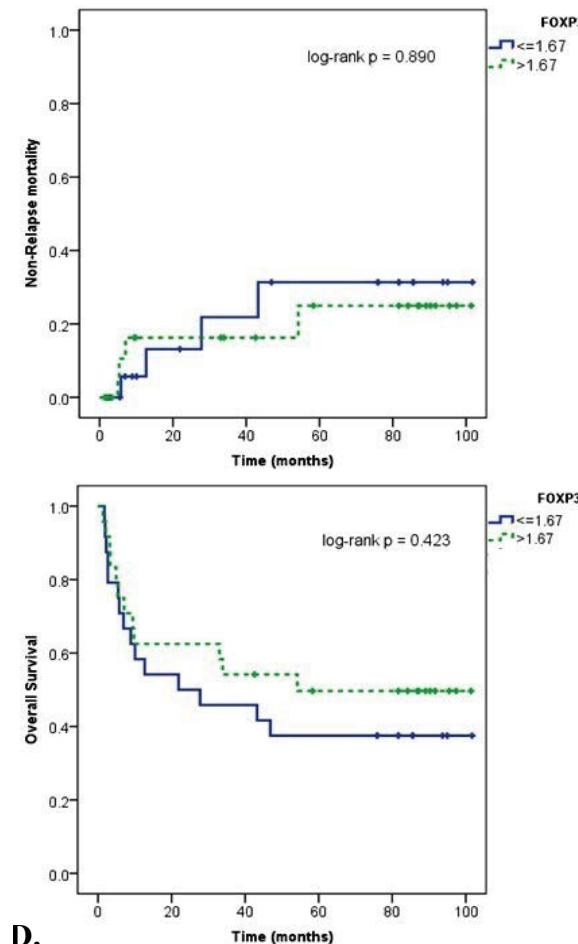

B.

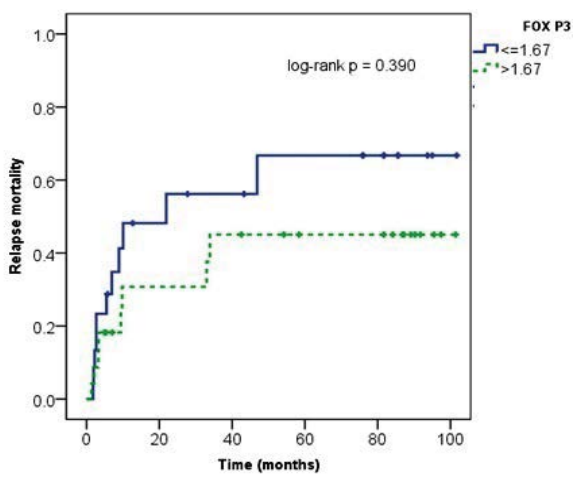

C.

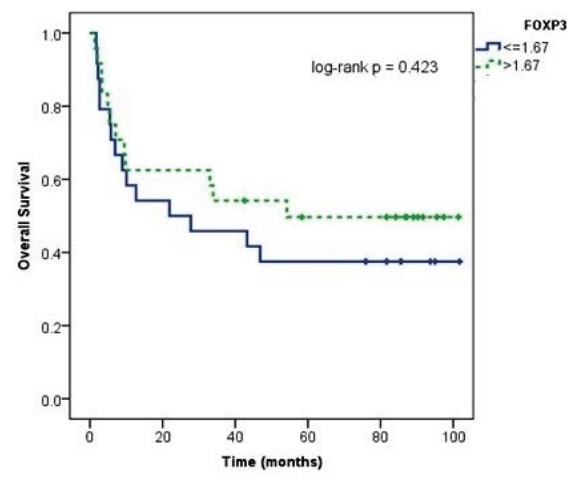

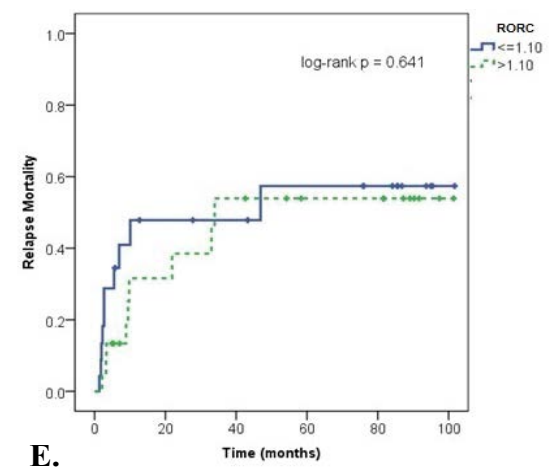

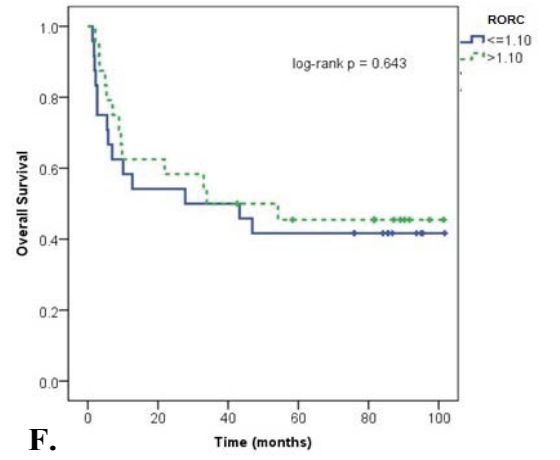

Figure 3: Ratio of FOXP3 and RORC expression and clinical outcomes. The median expression of FOXP3 was 1.67 in patients undergoing allogeneic HCT at the time of aGVHD. A) Non-relapse mortality; B) Relapse Mortality; C) OS in patients with aGVHD divided according to the median of FOXP3 expression (high $>1.67$ and low < 1.67). The median expression of RORC was 1.10 in patients undergoing allogeneic HCT at the time of aGVHD; D) Non-relapse mortality; E) Relapse Mortality; F) OS in patients with aGVHD divided according to the median of $R O R C$ expression (high $>1.10$ and low $<1.10$ ).

median FOXP3 (1.67) and RORC (1.10) expression values, measured at the time of aGVHD. The small number of patients within CGVHD group did not allow such analysis. FOXP3 expression (Figure 3A, Figure 3B and Figure 3C) and RORC (Figure 3D, Figure 3E and Figure 3F) did not present impact on OS and relapse-related or not related mortality.

\section{Discussion}

Our study confirmed the role of Th17 and Treg related genes in the pathogenesis of GVHD. We found increased expression of RORC in cGVHD compared to patient with no GVHD. We also found a decreased FOXP3 expression at the time of GVHD onset when compared to its respective samples before $\mathrm{HCT}$, in patients undergoing allogeneic HCT from MRD. Although these results could have therapeutic relevance, we could not identify genes' expression values to be used to predict GVHD onset, overall survival, non-relapse or relapse-related mortality.

Initially, performed an analysis of all patients assigned in this study ( $N=51)$ to assess the expression of FOXP3 and RORC in different times proposed: At aGVHD and CGVHD onset and at $D+90$ for patients who did not develop any GVHD. This last moment was chosen with the aim of having more homogeneous groups and before the possibility of occurring cGVHD. Our results demonstrated a similar behavior of both genes between healthy controls and patients who did not develop GVHD.
The higher expression of FOXP3 at cGVHD onset compared with controls, no GVHD and aGVHD contradicts several studies, which showed a decreased frequency of Treg from peripheral blood of patients with cGVHD $[29,30]$. However, the most clinically relevant information in this study is the increase of RORC expression in cGVHD compared to patient without GVHD. There are few studies in the literature investigating the role of Th17 lymphocytes in CGVHD. Dander, et al. [31] also observed a significant increase in the number of Th17 cells in the blood of patients with active cGVHD. However, other studies in humans have failed to demonstrate the increase expression of Th17 cells in peripheral blood after HCT at the time of GVHD $[32,33]$.

We performed a paired analysis of sixteen patients with their respective samples before HCT and at the time of aGVHD and we observed a statistically significant decrease in FOXP3 expression at aGVHD onset, confirming previous clinical studies [12,15,34,35]. Similarly, we conducted a matched analysis among patients who developed cGVHD, and also decreased expression of FOXP3 was found, consistent with some published work [29,36-38]. There was no difference in the expression of $R O R C$ at the time of aGVHD and CGVHD. Dlubek, et al. [39] investigated the presence of IL-17 producing cells in peripheral blood of patients undergoing HCT. Although all patients had shown increase of cells producing IL-17, a minority of patients developed aGVHD and these had lower proportions of $\mathrm{CD} 4^{+}$cells producing IL-17 on the 
aGVHD onset. One hypothesis suggested by the author was that these cells could have migrated to the affected tissues during the clinical manifestations of GVHD, justifying its absence in the peripheral blood. Other study evaluated not only the peripheral blood as well as the skin of patients with cutaneous aGVHD through biopsy and also failed to show an increase in IL-17 producing cells in both sites [32]. Fulton, et al. [40] demonstrated in a murine model that the use of RORC-deficient donor $T$ cells results in attenuated aGVHD severity and lethality. Thus, although there is strong evidence of involvement of Th17 cells in the pathophysiology of acute and chronic GVHD, further elucidation of the mechanisms of action of these cells in GVHD is needed [41].

GVHD remains one of the major determinants of survival, post-transplant morbidity and quality of life of patients submitted to allogeneic HCT, especially when immunosuppression is required to control this complication. The presence of moderate to severe aGVHD itself confers adverse prognosis for patients, since half of them do not respond to traditional therapy based on steroids. Therefore, it is essential to develop tools to predict and better understand the biological mechanisms responsible for this type of immune response [37].

An effective immune response is required for successful tumor eradication and numerous strategies are being tested to enhance specificity, maximize GVT, and minimize GVHD after adoptive immunotherapy. In this scenario, Treg immunotherapy is a promising strategy for the therapeutic control of GVHD [7,24]. Several early-phase clinical trials were performed where Tregs were given to HCT recipients to prevent GVHD [42-44]. Although a limited number of patients were treated in these trials, the initial data suggested that Tregs diminish GVHD without increasing the risk of disease recurrence or infection. Interestingly, despite their clinical use, it is still unclear how Tregs function to prevent GVHD. Regulatory T cells may have adverse effect: Tregs are a major concern in cancer immunology where they have documented inhibitory activity on antitumor immunity. Just as T-cell depletion has reduced the graft-versus-malignancy effects of allogeneic hematopoietic transplantation, infusion of Tregs may potentially increase the risk of recurrent malignancy. Therefore, this can only be assessed in larger scale human trials and the main challenge in hematopoietic transplantation remains the prevention of GVHD without impairing graft-versus malignancy effects [45].

One limitation of this study is the small number of cases. Other limitation is that most published studies have used flow cytometry to characterize Treg and Th17 lymphocytes populations, not qPCR. It is noteworthy that FOXP3 transcripts analysis in $\mathrm{CD}^{+}$population by qPCR showed comparable results on the same pop- ulation of $\mathrm{CD} \mathrm{CD} 4^{+} \mathrm{FOXP3}^{+} \mathrm{CD} 25^{+}$by flow cytometry [4]. QPCR has also the advantage of being highly sensitive and needs a small amount of material, relevant features when it is intended to study a numerically small cell population or when searching for a biomarker [46].

\section{Acknowledgements}

This work was supported by Fundação de Amparo à Pesquisa do Estado de São Paulo (FAPESP) (2010/176686), Brazil.

\section{Conflict of Interest Statement}

The authors declare that they have no conflict of interest.

\section{References}

1. Ferrara JL, Levine JE, Reddy P, Holler E (2009) Graft-versus-host disease. Lancet 373: 1550-1561.

2. Gyurkocza B, Rezvani A, Storb RF (2010) Allogeneic hematopoietic cell transplantation: The state of the art. Expert Rev Hematol 3: 285-299.

3. Socié G, Blazar BR (2009) Acute graft-versus-host disease: From the bench to the bedside. Blood 114: 4327-4336.

4. Rezvani K, Mielke S, Ahmadzadeh M, Kilical Y, Savani BN, et al. (2006) High donor FOXP3-positive regulatory T-cell (Treg) content is associated with a low risk of GVHD following HLA -matched allogeneic SCT. Blood 108: 1291-1297.

5. Yu Y, Wang D, Liu C, Kaosaard K, Semple K, et al. (2011) Prevention of GVHD while sparing GVL effect by targeting Th1 and Th17 transcription factor T-bet and RORyt in mice. Blood 118: 5011-5020.

6. Sakaguchi S, Ono M, Setoguchi R, Yagi H, Hori S, et al. (2006) Foxp3+ CD25+ CD4+ natural regulatory T cells in dominant self-tolerance and autoimmune disease. Immunol Rev 212: 8-27.

7. Colonna L, Florek M, Leveson-Gower DB, Sega El, Baker $\mathrm{J}$, et al. (2013) IL-17 gene ablation does not impact Treg-mediated suppression of graft-versus-host disease after bone marrow transplantation. Biol Blood Marrow Transplant 19: 1557-1565.

8. Johnson BD, Konkol MC, Truitt RL (2002) CD25+ immunoregulatory T-cells of donor origin suppress alloreactivity after BMT. Biol Blood Marrow Transplant 8: 525-535.

9. Xia G, Truitt RL, Johnson BD (2006) Graft-versus-leukemia and graft-versus-host reactions after donor lymphocyte infusion are initiated by host-type antigen-presenting cells and regulated by regulatory $T$ cells in early and long-term chimeras. Biol Blood Marrow Transplant 12: 397-407.

10. Taylor PA, Lees CJ, Blazar BR (2002) The infusion of ex vivo activated and expanded CD4(+)CD25(+) immune regulatory cells inhibits graft-versus-host disease lethality. Blood 99: 3493-3499.

11. Trenado A, Sudres M, Tang Q, Maury S, Charlotte F, et al. (2006) Ex vivo-expanded CD4+CD25+ immunoregulatory T cells prevent graft-versus-host-disease by inhibiting activation/differentiation of pathogenic T cells. J Immunol 176: 1266-1273.

12. Miura Y, Thoburn CJ, Bright EC, Phelps ML, Shin T, et al. (2004) Association of Foxp3 regulatory gene expression with graft-versus-host disease. Blood 104: 2187-2193. 
13. Zhai Z, Sun Z, Li Q, Zhang A, Liu H, et al. (2007) Correlation of the CD4+CD25high T-regulatory cells in recipients and their corresponding donors to acute GVHD. Transpl Int 20: $440-446$.

14. Meignin V, Peffault DL, Zuber J, Régnault A, Mounier N, et al. (2005) Numbers of Foxp3-expressing CD4+CD25high $T$ cells do not correlate with the establishment of long-term tolerance after allogeneic stem cell transplantation. Exp Hematol 33: 894-900.

15. Sanchez J, Casano J, Alvarez MA, Roman-Gomez J, Martin C, et al. (2004) Kinetic of regulatory CD25high and activated CD134+ (OX40) T lymphocytes during acute and chronic graft-versus-host disease after allogeneic bone marrow transplantation. Br J Haematol 126: 697-703.

16. Clark FJ, Gregg R, Piper K, Dunnion D, Freeman L, et al. (2004) Chronic graft-versus-host disease is associated with increased numbers of peripheral blood CD4+CD25high regulatory T cells. Blood 103: 2410-2416.

17. Kolls JK, Linden A (2004) Interleukin-17 family members and inflammation. Immunity 21: 467-476.

18. Shen F, Gaffen SL (2008) Structure-function relationships in the IL-17 receptor: Implications for signal transduction and therapy. Cytokine 41: 92-104.

19. Blazar BR, Murphy WJ, Abedi M (2012) Advances in graftversus-host disease biology and therapy. Nat Rev Immunol 12: 443-458.

20. Carlson MJ, West ML, Coghill JM, Panoskaltsis-Mortari A Blazar BR, et al. (2009) In vitro-differentiated TH17 cells mediate lethal acute graft-versus-host disease with severe cutaneous and pulmonary pathologic manifestations. Blood 113: $1365-1374$.

21. Nakae S, Komiyama $Y$, Nambu A, Sudo K, Iwase M, et al (2002) Antigen-specific T cell sensitization is impaired in IL-17-deficient mice, causing suppression of allergic cellular and humoral responses. Immunity 17: 375-387.

22. Kappel LW, Goldberg GL, King CG, Suh DY, Smith OM, et al. (2009) IL-17 contributes to CD4-mediated graft-versushost disease. Blood 113: 945-952.

23. Yi T, Zhao D, Lin CL, Zhang C, Chen Y, et al. (2008) Absence of donor Th17 leads to augmented Th1 differentiation and exacerbated acute graft-versus-host disease. Blood 112: 2101-2110.

24. Pavletic SZ, Kumar S, Mohty M, de Lima M, Foran JM, et al. (2010) NCl First international workshop on the biology, prevention, and treatment of relapse after allogeneic hematopoietic stem cell transplantation: Report from the committee on the epidemiology and natural history of relapse following allogeneic cell transplantation. Biol Blood Marrow Transplant 16: 871-890.

25. Przepiorka D, Weisdorf D, Martin P, Klingemann HG, Beatty $\mathrm{P}$, et al. (1995) 1994 consensus conference on acute gvhd grading. Bone Marrow Transplant 15: 825-828.

26. Filipovich AH, Weisdorf D, Pavletic S, Socie G, Wingard JR, et al. (2005) National Institutes of Health Consensus Development Project on Criteria for Clinical Trials in Chronic Graft-versus-Host Disease: I. Diagnosis and Staging Working Group Report. Biol Blood Marrow Transplant 11: 945-956.

27. Livak KJ, Schmittgen TD (2001) Analysis of relative gene expression data using real-time quantitative PCR and the 2(-Delta Delta C(T)) method. Method 25: 402-408.

28. Braga WM, da Silva BR, de Carvalho AC, Maekawa YH, Bortoluzzo AB, et al. (2014) FOXP3 and CTLA4 overex- pression in multiple myeloma bone marrow as a sign of accumulation of CD4(+) T regulatory cells. Cancer Immunol Immunother 63: 1189-1197.

29. Zorn E, Kim HT, Lee SJ, Floyd BH, Litsa D, et al. (2005) Reduced frequency of FOXP3+ CD4+CD25+ regulatory $\mathrm{T}$ cells in patients with chronic graft-versus-host disease. Blood 106: 2902-2911.

30. Li Q, Zhai Z, Xu X, Shen Y, Zhang A, et al. (2010) Decrease of CD4(+)CD25(+) regulatory $T$ cells and TGF-beta at early immune reconstitution is associated to the onset and severity of graft-versus-host disease following allogeneic haematogenesis stem cell transplantation. Leuk Res 34: 1158-1168.

31. Dander E, Balduzzi A, Zappa G, Lucchini G, Perseghin $\mathrm{P}$, et al. (2009) Interleukin-17-producing T-helper cells as new potential player mediating graft-versus-host disease in patients undergoing allogeneic stem-cell transplantation. Transplantation 88: 1261-1272.

32. Ratajczak $P$, Janin A, Peffault de Latour R, Leboeuf C, Desveaux $A$, et al. (2010) Th17/Treg ratio in human graft-versus-host disease. Blood 116: 1165-1171.

33. Broady R, Yu J, Chow V, Tantiworawit A, Kang C, et al. (2010) Cutaneous GVHD is associated with the expansion of tissue-localized Th1 and not Th17 cells. Blood 116: 5748-5751.

34. Wolf D, Wolf AM, Fong D, Rumpold H, Strasak A, et al. (2007) Regulatory T-cells in the graft and the risk of acute graft-versus host disease after allogeneic stem cell transplantation. Transplantation 83: 1107-1113.

35. Hoffmann $P$, Ermann J, Edinger M, Fathman CG, Strober $S$ (2002) Donor-type CD4(+)CD25(+) regulatory T cells suppress lethal acute graft-versus-host disease after allogeneic bone marrow transplantation. J Exp Med 196: 389-399.

36. Ukena SN, Grosse J, Mischak-Weissinger E, Buchholz S, Stadler M, et al. (2011) Acute but not chronic graft-versushost disease is associated with a reduction of circulating CD4(+)CD25(high)CD127 (low/-) regulatory T cells. Ann Hematol 90: 213-218.

37. Koreth J, Matsuoka K, Kim HT, McDonough SM, Bhavjot Bindra, et al. (2011) Interleukin-2 and regulatory T cells in graft-versus-host disease. N Engl J Med 365: 2055-2066.

38. Soiffer R (2008) Immune modulation and chronic graft-versus-host disease. Bone Marrow Transplant 42: S66-S69.

39. Dlubek D, Turlej E, Sedzimirska M, Lange J, Lange A, et al. (2010) Interleukin-17-producing cells increase among CD4+ lymphocytes before overt manifestation of acute graft-versus-host disease. Transplant Proc 42: 3277-3279.

40. Fulton LM, Carlson MJ, Coghill JM, Ott LE, West ML, et al. (2012) Attenuation of acute graft-versus-host disease in the absence of the transcription factor RORyt. J Immunol 189: 1765-1772.

41. Normanton M, Marti LC (2013) Current data on IL-17 and Th17 cells and implications for graft versus host disease. Einstein (Sao Paulo) 11: 237-246.

42. Brunstein CG, Miller JS, Cao Q, McKenna DH, Hippen KL, et al. (2011) Infusion of ex vivo expanded T regulatory cells in adults transplanted with umbilical cord blood: Safety profile and detection kinetics. Blood 117: 1061-1070.

43. Di lanni M, Falzetti $F$, Carotti $A$, Terenzi $A$, Castellino F, et al. (2011) Tregs prevent GVHD and promote immune reconstitution in HLA-haploidentical transplantation. Blood 117: 3921-3928. 
44. Horch M, Nguyen VH (2012) Regulatory T-cell immunotherapy for allogeneic hematopoietic stem-cell transplantation. Ther Adv Hematol 3: 29-44.

45. Komanduri KV, Champlin RE (2011) Can Treg therapy prevent GVHD? Blood 117: 751-752.
46. Smith CJ, Osborn AM (2009) Advantages and limitations of quantitative PCR (Q-PCR)-based approaches in microbial ecology. FEMS Microbiol Ecol 67: 6-20. 